\title{
Preface
}

\section{Transdisciplinary concepts and modelling strategies for the assessment of complex environmental systems Proceedings of the 12th Workshop on Large-scale Hydrological Modelling}

\author{
B. Schmalz, K. Bieger, and N. Fohrer \\ Dept. Hydrology and Water Resources Management, Ecology Centre, Kiel University, Germany
}

Since 1997 the series of the "Workshop on large-scale hydrological modelling" represents a discussion forum for the German-speaking research community in the field of hydrological modelling. The aim of the annual workshops is to document the state of research to this topic and to compile future research approaches and perspectives. The workshop of the year 2008 -held from 12 to 14 November 2008 in Salzaufocused on the exchange of experiences and idea about the heading "Interactions between atmosphere - hydrosphere biosphere: Model concepts for the integrated view of complex systems". The meeting comprises keynote presentations, oral and poster presentations. Special emphasis was set on the following topic areas:

- coupled modelling from the hydrological perspective

- coupled modelling from the climatological perspective

- anthropogenic interactions with the water cycle

This volume of "Advances in Geosciences" comprises 16 papers referring to the oral presentations and poster contributions. Applying hydrological models, some studies analysed discharge and/or nitrate loads in different landscapes (Lam et al.; Zhang et al.). Other presentations show the results from parameter estimations, sensitivity analyses and spatial data resolution (Conrad and Fohrer; Schmalz and Fohrer; Zhao et al.). Additionally, a simple GIS-based tool to estimate sediment pathways and a correction approach using SRTM DEM levels were presented (Kiesel et al.; Petersen et al.). Furthermore, land use effects or impacts of small-scale reservoirs and irrigation on water resources or flood generation were presented (Leemhuis et al., Menzel et al., Schaldach et al.;
Wahren et al.). Another focus was on the analysis and assessment of simulated climate change impacts on the water balance or their components such as evapotranspiration, groundwater recharge or snow sublimation (Bormann; Krause and Hanisch; Ludwig et al.; Wegehenkel; Wimmer et al.)

The editorial team would like to thank the authors and the reviewers of the submitted papers for their motivation and cooperation. With this volume, we hope to reflect the breadth of the interesting presentations and discussions of the workshop. We additionally thank Nadine Deisel of Copernicus Publication Office for agreeing to publish this issue and for the smooth publication process.

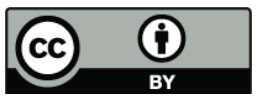

Correspondence to: B. Schmalz

(bschmalz@hydrology.uni-kiel.de)

Published by Copernicus Publications on behalf of the European Geosciences Union. 